\title{
DYSPNEA FROM NEUROPSYCHYATRIC PERSPECTIVE: A NARRATIVE REVIEW
}

\author{
Latinka Basara $^{\mathbf{1}}$, Nataša Jokić Begić ${ }^{2}$, Sanja Popović Grle ${ }^{1}$, Marko Jakopović ${ }^{1}$ \& Miroslav Samaržija ${ }^{1}$ \\ ${ }^{1}$ University Hospital Center Zagreb, Department for Respiratory Diseases, Zagreb, Croatia \\ ${ }^{2}$ Faculty of Humanities and Social Sciences, Department of Psychology, Zagreb, Croatia
}

received: 5.12.2017; $\quad$ revised: 12.2.2018; $\quad$ accepted: 28.2.2018

\section{SUMMARY}

Dyspnea or breathlessness is a term primarily used in respiratory medicine. Nevertheless, in the last fifteen years, studies from other fields focus on the affective component of this complex phenomenon due to the frequent observation that psychological states can cause or be caused by dyspnea. Research so far shows that besides the biological component, dyspnea has a strong emotional and psychosocial determinant. This means that apart from its biological factors, dyspnea and its intensity are affected by emotions, personality, anxiety and depression, etc. Individuals with psychiatric disorders, in the same conditions, will evaluate their dyspnea as more intense and disturbing compared to individuals without psychiatric comorbidity. Emotional states in healthy individuals can amplify the sense of dyspnea which is of extreme importance for clinical practice in order to consider the whole person and not just the symptom which is being presented. Also, dyspnea seems to be frequent complaint in some groups of patients with psychiatric disorders (e.g.panic disorder), where the fear of suffocation is presented as clinical symptom. Futher research of dyspnea as a complex, multicomponent phenomenon, can contribute to better treatment options and better differential diagnosis concerning possible psychiatric background of physical symptoms.

Key words: dyspnea - breathlessness - "mental health" - anxiety - depression - "psychiatric disorder" - "anxiety sensitivity"

$* * * * *$

\section{INTRODUCTION}

Dyspnea (Greek $d y s$ - "painful," "difficult”; pneuma - "breath") is a term used to describe a specific sensation of difficult breathing (Meek et al. 1999) which includes uncomfortable, conscious breathing, breathlessness and/or „air hunger“ (American Thoracic Society 1999). Although it represents an important clinical symptom in many physical diseases (respiratory, cardiovascular, neuromuscular, malignant, etc.), under certain circumstances it can be a symptom in healthy subjects. Dyspnea can also be present in some psychiatric disorders - for instance - panic disorder, depression and anxiety which makes it an interdisciplinary phemomenon. A Japanese study from 2015 showed that dyspnea has been reported as a presenting symptom in general practitioner's office in $8.1 \%$ of then nondiagnosed psychiatric patients (Ishikawa et al. 2015). In anxious individuals, staying out of breath can be a known trigger for panic attack. It also seems that sighing and taking deep breaths can be a calming factor in many emotional states but it can also add to the sensation of breathlessness. The result being that an individual can interpret dyspnea wrongly and visit emergency rooms or general practitioners more often than needed. Wrongly understood and presented symptom can lead in a different diagnostic direction. On the other hand, psychiatric comorbidity is somewhat usual in individuals with already diagnosed pulmonary obstructive diseases (van Manen et al. 2001, Dahlen \& Jansson 2002). This is understandable having in mind the following vicious circle: after the physical sensation of having strong dyspnea most individuals will feel fear from staying out of bretah and ultimately suffocating. This results in even more fear and shallow breathing (hyperventilation) and panic-like gestures that ultimately create an even stronger need for air, thus - stronger dyspnea. Dyspnea causes more fear and the person is constantly in the panic-like stage of dyspnea.

Data from some international studies report of the connection that respiratory symptoms have with anxiety and depression (Neuman et al. 2006) describing dyspnea as a factor in the development of psychiatric disorders but also the manner in which a psychiatric disorder can intesify dyspnea sensation. Nevertheless, the cause and effect relationship between dyspnea and anxiety and depression ceases to be clarified. In the prospective study of Neuman et al. (2001), for nine years the authors were following changes in individual's psychological status in regards to reported dyspnea with the idea of identifying a cause and effect relationship. The results have confirmed that in the nine year period symptoms of anxiety and depression were important for the onset of dyspnea, but there was less evidence that dyspnea can cause psychological symptoms. These results are consistent with the results that will follow in the literature review, indicating that some psychological characteristics as well as some emotional states can act as dyspnea amplifiers, consequently reenforsing the initial idea about the importance of considering psychosocial background and possible psychiatric contribution in some physical symptoms and states. 


\section{DYSPNEA BETWEEN NEURO- PSYCHOPHISIOLOGY AND PSYCHODYNAMICS}

The experience of difficult breathing may have different pathophysiologic origins. What we predominantly believe is that chemoreceptors in blood vessels of the brain and spinal cord as well as mechanoreceptors in thoracic wall, lungs and airways are all engaged in the automatic adjustment and regulation of the breathing pattern and frequention (Meek et al. 1999). Depending on the „input“ that comes from these structures to breathing centers in the brain, a new message is being transmitted to respiratory muscles, carrying informations about the needed change in frequency and breathing pattern. At the same time a „сорy“ of this message is being sent to higher brain centers causing consciousness about the transmitted message of needed change in breathing. One assumption states that it is in this moment that consciousness about needing more air is created, meaning that this could also be a crucial moment in dyspnea sensation. The „neuro-mechanical“ theory by Campbell and Howell from 1960. (Meek et al. 1999) claims that dyspnea comes from the discrepancy in the signals sent from peripheral receptors to the brain (about the muscle effort) and the ones being transmitted from the brain to respiratory muscles. But, we are also aware of the fact that emotional and psychological characteristics play a role in dyspnea sensation and so far conducted researches indicate that this is because there are more than one component of dyspnea.

\section{Two components of dyspnea}

For the long period of time dyspnea was considered to be a unidimensional phenomenon. Thanx to imaging techniques (PET- Positron Emission Tomography) and fMR - functional Magnetic Resonance) we now differentiate: dyspnea's sensoric sensation, neural activation (caused by the stimulation of the pheripheral receptors) and the perception of dyspnea. So, by understanding dyspnea as two dimensions phenomenon - sensoric and affective - we can better understand and atribute dyspnea to a specific trigger in certain groups of individuals. Simplified, sensoric dyspnea can be evaluated by answering the question „How intense is your dyspnea? “ while the affective dimension answers to a question „How unpleasant/distressing is your dyspnea?

Using brain imaging techniques, Von Leupoldt et al. (2008) found that sensoric and affective processing of dyspnea is separated. The same author identified areas of the brain included in those two separated processes: right insular cortex, rigt amygdala and medial thalamus for the affective component of dyspnea (discomfort) but not for sensoric component. Sensoric data processing activated posterior thalamus and sensorimotor cortex. This finding confirmed the theory of dual processing of dyspnea.
More importantly, according to this brain areas processing of dyspnea obviously shares a neural network with emotion processing. It is possible that this is the reason why there is a significant correlation between dyspnea intensity and its affective component (adversity) but not as much with its sensoric component (Von Leupoldt et al. 2009). The question is, whether frequent or prolonged activation of these brain structures (e.g. in respiratory patients, due to dyspnea) could lead to emotion activation to that extent to cause anxiety and depression for which we know are common comorbidities in respiratory patients. Research that followed these idea showed that positive emotions can reduce the sense of dyspnea while negative emotions can amplify it (Hrigstad et al. 2011).

In the study by De Peuter et al. (2007), the authors were trying to examine those two aspects in asthma patients. When pulmonary function was continuosly dropping during the experiment, the individuals whose affective estimations of dyspnea were preceeding the sensoric component, were generally more prone to report of more symptoms. The same effect was found for the individuals who had a pronounced trait anxiety. Furthermore, state anxiety was the best predictor of the affective component of symptoms while catastrophic thinking was the best predictor of sensoric symptoms in asthma exacerbation. In their research $\mathrm{Li}$ Wan et al. (2012) found that individuals with medically unexplained dyspnea get more sensitive to the affective component of dyspnea when presented with the repeated stimuli while healthy individuals had the opposite pattern.

\section{Interpretation and interoception in dyspnea}

In regards to catastrophic thinking and beliefs about symptoms, we mention the study by Hallas et al. (2012). The group of authors was examining beliefs about the disease in persons diagnosed with chronic respiratory diseases and how much are these beliefs connected to dyspnea and panic. One person's belief system about the disease, its course, possible threats and consequences as well as the beliefs one has about his/hers self-efficacy in symptom management that are activated by some adverse event (e.g. dyspnea) are of great interest to scientists because they represent a sort of context in which dyspnea can be analyzed.

Results of the study somewhat suggest that beliefs and the sense of controll one has over the symptoms can be a modifying variable affecting dyspnea sensation. As such, they can represent a manageable factor and help modify (reduce) symptoms of fear, panic and avoidance behavior in persons with chronic dyspnea. Results like these serve as a confirmation of the usefullness of cognitive-behavioral techniques in the treatment of dyspnea related anxiety being that the core goal of this approach is to modify catastrophic thinking and interpretations of bodily symptoms (Hallas et al. 2012). 
Earlier, we mentioned how in the light of better understanding and describing dyspnea and its mechanisms, some authors have studied the accuracy of interoception as a possible factor in the sensation of dyspnea. The reasearch from Pappens et al. (2010) showed that interoceptive threath (dyspnea - experimentally caused with resisitive load breathing) compared to an outher threath (experimentally caused, aversive picture watching) causes the same or stronger reactions of fear. To estimate fear, authors measured electrodermal reaction, startle eye blink reflex, subjective rating of fear, sense of violence and arousal. The only difference noticed was that in the interoceptive threath situation, the startle eye blink reflex did not appear which was explained by authors as self understanding since the threath was coming from within.

Interesting interpretation of this result can be found in the model presented by Craig (2003, from Pappens et al. 2010) which proposes that dyspnea is a „homeostatic emotion" together with hunger and visceral pain. All three have a role of „alarming“ the organism towards activity that will restore homeostasis. As such, says the author, they are probably activated by autonomic reaction, and since startle eye blink reflex is not homeostatic but a response to an outer threath - it is probably activated through different neural pathways.

\section{Psychosomatic aspect of dyspnea}

In our literauture search, trying to idenfity whether there are psychological correlates of dyspnea, we stepped into the field of possible psychosomatic characteristics of dyspnea. Some of the articles date before our search of 2000 to present and some even before 1960 which shows the long lasting interest that dyspnea is producing among researchers. However, most of recent studies in this field that were found during search examine dyspnea in a certain respiratory disease which exceeds the frame of this article. We will mention the research done by Nowobilski (1999) in the atempt to try to explain the psychosomatic correlations in persons with asthma. The results showed that the levels of anxiety and depression were depending on the symptom (dyspnea) severiy and that there was a correlation between anxiety and expressed dyspnea. Like in some previous studies, author described the correlation between anxiety intensity and subjective dyspnea with pulmonary function test resuslts concluding of an existing relationship but still no causality.

\section{The function of dyspnea - an analitical view}

With the intention to comprehensively describe breathlessness, we mention yet another view of dyspnea - the psychoanalitical view. One of interesting sources were authors Dethlefsen \& Dahlke (2011) who have proposed and explained the possible and very different outlook on dyspnea (as all other bodily symptoms) than described in the so far text.
According to the authors, every physical symptom is a signal through which the body is trying to draw attention to the fact that consciousness has lost its harmony and that it has become ill. Body symptom is merely a signal and it alone doesn't need to be treated or examined. They state that modern medicine is so fascinated by the symptom itself that it oftenly omits the process of curing the whole person. Also, they propose that alowing the symptom to develop, really understanding it and not trying to fix it would eventually lead to restoring harmony and life without any symptoms.

As far as breathing is concerned, authors discuss asthma as a disease that has long been considered psychosomatic. According to this approach, being breathless means that individual is actually struggling with: 1) giving and taking (e.g.love); 2) with the desire to be locked away from everyone and everything, so that nothing comes in or out; 3) with the desire to dominate and to have power (which in return, is being supressed and directed inwardly) and 4) with defense from the dark things in life (which enables the individual to be better and „above“ others). From the author's point oof view, a person will be free of symptom once he/she manages to become aware (consciouss) of the real disbalance and accepts it or tries to mend it. In individuals with difficult breathing, the person should be asked a set of questions regarding the four above stated areas and by that, the authors presume - dyspnea would be cured at the very basis.

\section{DYSPNEA: A GATEWAY TO ANXIETY AND DEPRESSION}

As previously listed researches indicate, emotions and moods can modify dyspnea perception; either by different neural activation, by different interpretation or by the effect of environmental context/contrast, thus affecting the perception of the sensation's intensity and adversity.

\section{Dyspnea and anxiety}

Dyspnea and anxiety are common complaints among the persons with chronic pulmonary diseases. But, in some cases it can be a symptom in healthy subjects as well as in psychiatric population of patients.

Apart from being an important clinical symptom in respiratory patients, dyspnea also represents a symptom of anxiety especially among individuals with panic disorder or hyperventilation syndrome. Some studies have found a connection between dyspnea and anxiety unrelated to pulmonary function measured by $\mathrm{FEV}_{1}$ (Neuman et al. 2006) and among persons with no respiratory disease (Giardino et al. 2010, Rimington et al. 2001, Dales et al. 1989, from Leivseth 2012), which lead other autors to believe that this two construcs may be correlated. 
An important epidemiological study from Norway The Nord-Trøndelag Health (HUNT) study (Leivseth et al. 2012) was examining the connection between impaired pulmonary function and anxiety with dyspnea. Results showed an independent influence pulmonary function and anxiety have on dyspnea. The found interaction was referring to conclusion that at the higher levels of pulmonary function impairment, persons with higher anxiety report of more intense dyspnea in comaprison to persons without anxiety. Having this in mind, we could be asking ourselves- does anxiety affect dyspnea directly or just the perception of dyspnea? Also, does anxiety influence dyspnea through some neural mechanism or indirectly, through a certain psychological variable (e.g. anxiety sensitivity or trait anxiety)?

These and similar questions were the subject of many research that followed. Some have managed to demostrate the connection between anxiety and dyspnea but still without a clear cause and effect relationship. Bailey et al. (2004) described the vicious cirle of anxiety and dyspnea. The model explains that an individual gets anxious by anticipating the situation in which he/she may become breathless. The very notion of possible danger and adversity of being breathless will cause fear and „fight of flight“ reaction resulting in even stronger need for air. This will result in more frequent and shallow breathing called hyperventilation that causes dyspena to worsen. The desrcibed model, however, explains indirect and not direct (physiological) connection between the two constructs - anxiety and dyspnea.

Carrieri-Kohlman et al. (2010) conducted a research in which the relationship of these two terms is presented in a more specific way. They propose that dyspnea related anxiety and dyspnea related distress are actually two concepts separated from general anxiety and negative affect. As such, according to the authors, they should be measured as separated intervention outcomes and not under general anxiety. Only one more study we found had separated these two kinds of anxiety. As far as physical activity is concerned in patients with chronic obstructive pulmonary disease - COPD, authors De Voogd et al. (2011) have concluded that dyspnea related anxiety disapeares after exercising while general anxiety stayes the same even after a workout which could indicate that these two kinds of anxiety really need to be measured separately.

Interesting as it sounds, in our further search we found no more studies emphasizing this distinction and most of other authors have mainly focused on investigating general anxiety in relation to dyspnea.

So far, studies conducted on healthy individuals as well as on persons with respiratory diseases - mainly asthma and COPD - have shown that even with the same baseline resiratory status, after intentionally evoked ventilation changes - individuals with high levels of anxiety tend to report of more respiratory symptoms in comparison to the ones with low levels of anxiety (de Peuter et al. 2008, Giardino et al. 2010, Li et al. 2006, Voegele \& Von Leupoldt 2008, from Von Leupoldt 2011).

But, there are other studies that contradict the above mentioned results arguing that individuals with high or low levels of anxiety do not necessarily overestimate or wrongly identify respiratory symptoms but rather that the affective context during the examination is responsable for making such kinds of respiratory stimuli ratings (Bogaerts et al. 2005).

So, as we have previously mentioned, it remains unclear whether eleviated anxiety is connected to objectively measurable neural processing of respiratory stimuli. The intention to answer this question came from a study done by Von Leupoldt et al. (2011). The authors have examined whether affective context (which was succesfully manipulated in the study) can affect respiratory stimuli perception in relation to subject's low or high anxiety levels. The idea was to find the potential neural mechanism that would explain the direct dyspnea - anxiety connection. Results have shown that individuals with higher anxiety reported more respiratory stimuli when occlusions were given in the affective and not during neutral context, whereas, individuals with low anxiety showed the opposite pattern. Moreover, the results indicated that anxiety affects (in a context dependent manner) higer-order neural processing of respiratory stimuli (consciousness) but not early sensory processing. These findings suggested a possible underlying neural mechanism responsable for increased perception of respiratory stimuli in anxious individuals. The authors suggest a possible explanation of the results by which the unpleasant affective context made respiratory stimuli more relevant for the individual therefore creating a stronger motivation to percieve respiratory stimuli. This was prevoiusly found in other populations of invidiuals - healthy subjects as well as in patients with asthma. The authors emphasize that it is important to futher examine why affective context is affecting respiratory stimuli perception in anxious (but healthy) individuals and how it is acquired. Also, whether such effect can be found in individuals with respiratory diseases and would they therefore profit from psychotherapeutic or pharmaceutical interventions for reducing anxiety (Von Leupoldt 2011).

It is known how stimuli perception and interpretation have an important role in the onset of anxious reaction and anxiety disorder. Having the above described study's results in mind - that anxiety affects higherorder neural processing and not the sensoric respiratory stimuli processing - it could bring us closer to the conclusion that anxiety and dyspnea are connected indirectly.

\section{Dyspnea characteristics in respiratory patients with comorbid anxiety disorder}

Livermore et al. (2008) found that COPD patients with comorbid panic disorder or panic symptoms report of greater induced dyspnea during resistive load 
breathing in comparison to COPD patients without panic symptoms even though both groups of patients had similar baseline pulmonary limitations.

Also, research on persons suffering from asthma with and without panic disorder showed that when subjected to metacholine test (used to provoke bronchial constriction, expecting to result in breathlessness) individuals with comorbid panic symptoms report of more psychological disstress in spite of small objectively caused physiological arousal. Also, during the mentioned test asthmatics with panic disorder render more panic-like symptoms in comparison with asthmatics without comorbid panic disorder. It is important to emphasize that in the study there was no evidence of stronger airway reactivity among individuals with panic disorder in comparison to ones without panic symptoms. This would imply that cognitive processing of the stimuli (interpretation) could be of importance in estimating dyspnea intensity. This finding could also explain why there is a certain percentage of poorer outcomes in treatment of asthma patients with comorbid panic disorder; it doesn't have to necessarily be due to the stronger bronchial reactivity but because of the emotional reaction paired with asthma symptoms (Boudreau et al. 2015).

An older research from Carr et al. (1992) investigated the dominant reasons for fear in persons with asthma compared to persons with panic disorder. Results showed that dyspnea causes panic-like fears in asthmatics but not in persons with panic disorder (either as separated disorder or when it is comorbid to asthma) and that dyspnea doesn't explain a significant portion of panic fear variance in persons with panic disorder. This finding could come as a surprise because we would expect breathlessness to cause much of panic fear in panic disorder. One of the explanation could be that triggers for panic attack can be diverse and not all include staying out of breath or fear of suffocation.

Further on, in a study by Giardino et al. (2010) authors were dealing with the influence a panic disorder may have on dyspnea in persons with COPD. The results showed that persons with COPD with or without comorbid panic disorder didn't differ in interoceptive sensitivity to respiratory stimuli (measured with the threshold for difficult breathing). However, results also show that the two groups differ significantly in their estimation of dyspnea when asked to continue breathing against resistance. Dyspnea was estimated as more intense among persons with COPD and comorbid panic disorder which is in concordance to earlier mentioned theory about the importance of cognitive aphraisal as the key factor. The difference is lost when the two groups were controlled for anxiety sensitivity. This could mean that anxiety sensitivity is a mediating variable for dyspnea sensation in COPD patients.

In their study, Chan et al. (2014) were investigating the processing of respiratory stimuli in persons with generalized anxiety disorder. They managed to show the modulating effect that clinicaly significant anxiety has on neural processing of dyspnea, that was different from the one exibited in the healthy group of subjects. The changes in EEG signal that include latency and smaller amplitudes in some areas were found in the case of emotional information processing but not for sensoric data on dyspnea. This finding is an indication of the influence of the affective state on the changes in dyspnea perception among persons with generalized anxiety disorder. The authors conclude that the difference in the processing of the affective and sensoric components of dyspnea will differ depending on the „context“" in which the dyspnea occures.

In regards to specific respiratory diseases and anxiety, studies show an increased prevalence of generalized anxiety, panic disorder and more frequent panic atacks in clinical samples of individuals with asthma in comparison to general population. Also, there is a significant probability in persons with asthma in comparison to general population to develop some anxiety disorder, panic disorder or panic atacks (Deshmukh et al. 2007). This may not come as a surprise due to the variable, unpredictive and potentialy threatening nature of asthma. Some theories explain this comorbidity proneness through somatic effects of hyperventilation combined with fear of dyspnea (interpretation) and abnormal sensitivity of the receptors in central nervous system (CNS) to carbon dioxide which set of the reaction to breathe in more air.

Other theories emphasize that the unpredictible and often uncontrollable dyspnea in asthma plays an important role in etiology of panic disorder and that this is the reason for connection between these two entities.

Fear of suffocation has been studied for its role in panic attacks (Ley 2001) with the assumption that individuals with panic disorder have a higher interoceptive reactivity. By including healthy (without panic disorder) close relatives of subjects with panic disorder in their studies, researchers tried to reach conclusions on the potential family vulnerability for dyspnea sensation. The studies used 35\% $\mathrm{CO}_{2}$ to induce „inner“ symptoms like dyspnea and other bodily sensations to subjects and their close relatives and found that the subject's close relatives also had a pronounced reactivity in comparison to non-related individuals. But, data from similar studies is not consistent so any further generalization od this finding is not possible.

Serap Monkul et al. (2010) have not managed to confirm their hypothesis that having a close relative with panic disorder and sensitivity to $\mathrm{CO}_{2}$ provocation is a predictor of such sensitivity and panic disorder in their healthy relative. But in the situation of comorbid panic disorder in respiratory disease, it seems that the person is even more sensitive to provocation with $35 \% \mathrm{CO}_{2}$ Schmidt \& Richey (2008) have conducted a study in which they showed how individuals with panic disorder and high social anxiety (while controlling variables like anxiety sensitivity and negative affect) are more susceptible to the provacation with $35 \% \mathrm{CO}_{2}$ in comparison to individuals without panic disorder or social anxiety. 
Individuals with panic disorder and high social anxiety had 2.5 times bigger risk for having an anxious reaction to carbon dioxide provocation in comparison to those with low social anxiety. With such finding authors have demostrated a potential unique relationship between anxious reaction to $35 \% \mathrm{CO}_{2}$ and social anxiety, that could preceed panic attacks.

Futher on, Pappens et al. (2012) have been researching whether fear of suffocation (an important factor in some anxiety disorders) can cause changes in respiratory and affective response to difficult breathing in healthy individuals. It is well known that people tipically increase brething frequency when faced with fear and that more intensive breathing can lead to drying and cooling of airways. This can intensify the perception of dyspnea, consequently intesify fear and lead to asthmatic atack (in asthma patients) or panic atack or both (Lehrer, Isenberg \& Hochron, 1993; Meuret \& Ritz, 2010; from Pappens et al. 2012).

Results of the mentioned study have shown that during the presentation of the stimuli (resistive load breathing) individuals with stronger fear of suffocation have estimated experiencing higher levels of arousal and discomfort in comparison to individuals without suffocation fear. Also, concordant to previous finding it was shown that breathing frequency is connected to fear and that fear from suffocation is greater as the loaded breathing lasted longer. With longer lasting loaded breathing - the breathing frequency also increased. During increased frequency of breathing it is expected for the muscles to tire which can cause subjective sense of not having enough air - dyspnea.

With that conclusion, this study demonstrates the reenforcing relationship of fear and dyspnea and confirms presumptions of a couple of previous authors who suggested the connection between fear and inadaptive breathing pattern (Bouton et al. 2001, Clark 1986, Klein 1993, Ley 1989, from Pappens et al. 2012).

However, it should be noted that the described experiment had limitations due to very small sample (only 27 subjects) and all subjects were females. This could be a factor since we know that there are differences in reacting to loaded breathing among males and females (Aleksander-Miller \& Davenport 2010).

\section{Dyspnea and anxiety sensitivity}

With so far presented studies we wanted to give a more broader outlook on the connection between anxiety and dyspnea. In the following studies dyspnea was explored in connection to anxiety sensitivity (AS), previously mentioned as a possible mediating variable in dyspnea sensation. Anxiety sensitivity is considered to be a trait defined as fear from anxiety symptoms. Individuals with high anxiety sensitivity are keene in detecting changes in their body, percieve any sensation and usually interpret them catastrophically. This could put them at risk for developing a panic disorder.
In the research from Alius et al. (2013), authors aimed to investigate whether individual differences in anxiety sensitivity could moderate subjective dyspnea sensation and fear of suffocating during intentionally evoked dyspnea by resistive load breathing. The results showed that the threshold for dyspnea was the same for individuals with high and low anxiety sensitivity and that fear of suffocation did not affect dyspnea treshold. But, affective estimations of dyspnea were significantly higher (during same respiratory loads) for individuals with higher anxiety sensitivity and fear of suffocation compared to individuals with less anxiety senstitivity. One of the proposed explanation for this finding could be that more fearful individuals actually have a better sensitivity to interoceptive signals. But, since the study objectively measured dyspnea treshold and concluded that there were no objective difference in sensitivity to dyspnea between high and low anxiety sensitivity group, other explanation might apply.

The latter is concordant with other studies suggesting that individuals who are prone to feeling fears and panic are actually worse in correct recognizing of interoceptive signals (Asmundson et al. 1993, Van der Does et al. 2000, from Alius et al. 2013).

Opposite explanations are characterized by the idea that individuals with higher anxiety sensitivity have a correct interoceptive signal recognition but that the expectation of the signal's consequence is overcatastrophic and leads to panic reactions.

In another study, designed to determine the role anxiety sensitivity plays in dyspnea sensation, subjects with high and low anxiety sensitivity were inhaling air saturated with $20 \% \mathrm{CO}_{2}$ interrupted by breaks during which they were inhaling regular air. Results showed that during the test individuals with high AS changed their breathing pattern to faster and more shallow, follwed by faster heart rate in comparison to low AS subjects. This could be a consequence of anticipatory anxiety ultimatelly causing more dyspnea. In comparison to subjects with low AS, individuals with high AS had greater reactivity in their dyspnea sensation estimations (Blechert et al. 2013).

\section{Dyspnea and depression}

Compared to anxiety, the conducted literature search on depression and dyspnea produced far less reported research.

We mention the research from Calikoglu (2004) in which was shown that in women without cardiovascular difficulties and with a major depressive episode there is a much intense dyspnea in comaprison to healthy women without depression who had similar pulmonary function results, leading us to conclude about the connection of these two constructs.

In their qualitative research Bailey et al. (2004) have shown that COPD patients in comparison to other groups of patients have rated their symptoms of reactive depression significantly higher (without comorbid 
psychiatric disorders). But the authors emphasize that there was no correlation or cause and effect relationship found between dyspnea and depressive reaction (Light et al. 1985, McSweeny et al. 1982, Yellowlees et al. 1987).

Futher on, research show that depressive individuals tend to more often complain of physical, medically unexplained symptoms e.g. fatigue, reduced libido, sleep difficulties, chest pain, weight loos and dyspnea (Waxmen et al. 1985, Mathew et al. 1981, from Calikoglu, 2004) which can also indicate a certain existing relationship between dyspnea and depression. What is even more difficult for these individuals is that physical activity - so often recommended in mild depression (Vancampfort et al. 2015) - is often not possible in patients complaining of dyspnea due to the discomforted breathing.

In their research on COPD patients, Borges-Santos et al. (2015) have shown that individuals suffering from that chronic disease and have comorbid depression, report of significantly greater dyspnea. Also, individuals who besides depression have anxiety symptoms as well, report of having less controll over their disease even though some objective parameters (breathing pattern and toracic-abdominal mechanics) have been evaluated as similar.

There are other studies showing this connection as well. Goodwin et al. (2002) have shown that dyspnea is more frequent in depressed women compared to healthy ones, Takana et al. (2002) found that psychological difficulties are significantly related to dyspnea, Keller et al. (1992) have suggested that depression is a predictor for dyspnea and Gift \& Cahill (1990) have found that the level of dyspnea in COPD patients is related to physiological and psychological characteristics (Calikoglu 2004).

\section{DYSPNEA BETWEEN ANXIETY AND DEPRESSION}

If we compare anxiety and depression and their relationship to dyspnea we must mention the study of Petersen \& Ritz (2009) that hypothesized that anxiety has a different effect on respiratory sensations in comparison to depressive mood. Results from their research showed that depression was predicitive for ventilatory difficulties, obstruction of breathing and breathing pauses which is different from what we already now about the „energizing“ effects that anxiety has on breathing - intensifying ventilatory work through hyperventilation. This result could be interpreted in concordance with the long familiar interpretation of depressive mood. The idea states that depressive mood will lead to withdrawal, stillness and recuperation from stress reactions. So, the breathing pattern in depressive mood is concordant - also reffering to calmness, reduced ventilation, recuperation and withdrawal.
A sort of confirmation of these resutls could be the high comorbidity of depression and obstructive sleep apnea (OSA) where during sleep there are pauses in breathing due to respiratory restrictions (Schroeder \& O'Hara 2005, Petersen \& Ritz 2009). It was results like these that lead to the speculation that depression and OSA share a neurobiological „risk“ in the serotonergic system (Andrews \& Oei 2004, from Petersen \& Ritz, 2009). Low lewels of serotonin are connected to depression and lowered activity of neurons in the upper airways during sleep. Inhibitors of selective serotonin reuptake can reduce depression symptoms in persons with COPD (Ramasamy et al. 2006) and lower the frequency of breathing pauses during sleep (Veasey 2003, from Petersen \& Ritz 2009). This indicates a physiological connection between the two.

The other possibility how depression could be a part of pathophysiology of respiratory sensations is the fact that some studies have linked depression to the inflammation reaction of the organism (Strike et al. 2004, from Petersen \& Ritz 2009) which is also the case in some respiratory diseases characterized by dyspnea.

In regards to some earlier assumptions and findings that neuroticism is connected to more reports of disease symptoms and above described notion on depression, authors Howren \& Suls (2011) have tested two hypothesis: (1) that depression is connected to retrospective overreporting of body symptoms and (2) that anxiety is connected to present overreporting of body symptoms. The results have shown that depressive affect was connected to remembering more symptoms while neurotiscism didn't show that effect. In regards to the second hypothesis, the subjects have been randomised in experimental situations of anxious, depressive, angry, happy or neutral context (by inducing such mood through validated materials for emotion induction). It was demonstrated that during anxious affect the subjects tend to overreport current, actual syptoms. In direct comparison to depressive context - subjects from anxious context remember less past symptoms than do ones from depressive context, but report more actual current symptom than do ones from depressive context (Howren \& Suls 2011).

Besides this being an important finding for understanding breathing and some psychological constructs, this is also important for the demonstrated differences in coding and remembering information (symptoms, intensity, discomfort) in anxious versus depressive mood. This differences can affect the amount and the manner in which the symptoms are being reported by the patients to their physicians in general practises or emergency rooms.

In regards to all so far known about anxiety and the importance of quick reacting in order to remove oneself from the threath, and what we know about depression and its tendency to focus on past events - this finding can be valuable in etiology of some health behaviors. 


\section{CONCLUSION}

Dyspnea is a complex sensation consisting of two components - affective and sensoric. Each component of the sensation has different brain structures involved in the dyspnea processing thus leaving room for different environment stimuli to differently affect intensity and adversity sensation in every person. Some emotional states, like anxiety and depression can lead to greater dyspnea proneness. Anxiety and depression show a definite and specific relationship with dyspnea. Research suggest a certain „vicious cirle“ in which dyspnea causes anxiety and anxiety causes even more dyspnea due to hyperventilation. Depression has a different connection to dyspnea where one of the explanations is that breathlessness serves as a regulatory mechanism and homeostatic emotion motivating the body to take specific action to regenerate itself. In general, it has been found that anxiety and depression can explain more variance of subjective health status than some physiological variables like - $\mathrm{FEV}_{1}$ value (spirometric measure - forced expiratory volume in the first second) (Bentsen et al. 2008, from Leivseth et al. 2012). But, in reviewed literature we didn't find studies that would demonstrate or confirm a cause and effect relationship. Even though in clinical practice we can observe the relationship sometimes, or be aware of some causality, the strict cause and effect relationship will be hard to prove as long as there are respiratory healthy individuals who have constant dyspnea and persons with proven respiratory disease but report of no anxiety or depression.

Depression is mainly described as characteristics that affects overreporting about various body symptoms, not only dyspnea. If anxiety and depression exist as comorbidities in persons with pulmonary diseases they will tend to report of more pronounced dyspnea compared to persons with no psychiatric comorbidities.

Authors of this and similar findings inerpret this results as the consequence of the difference in perception among persons with anxiety and/or depression more so than because of some objective physiological state. As expected, the role of anxiety sensitivity has been demostrated in practicaly all studies and in a way that individuals with hightened anxiety sensitivity tend to percieve more bodily symptoms, including dyspnea. Some authors have excluded general anxiety from dyspnea related anxiety claiming that those are two different constructs and as such had to be investigated separately in order not to lose valuable data. Others propose a completely different outlook on dyspnea, stating that symptom is merely a symbol of distturbed psychological (not physiological) harmony and that breathless persons have difficulties in the psychosocial, not physical aspect.

In conclusion, a very fruitfull field with many research but with still some questions left unanswered. Further studies using imaging techniques should provide us with more data on individual differences in dyspnea sensation between specific population groups. Anxiety and depression could be much more easily understood as secondary to dyspnea because of the burden dyspnea brings to maintaining quality of life. But, the more interesting and complex finding from the future research would certainly be to learn much more on how anxiety or depression (cause) induce or highten dyspnea as well as all the factors adding to its sensoric and affective dymension.

\section{Acknowledgements: None.}

\section{Conflict of interest: None to declare.}

\section{Contribution of individual authors:}

Latinka Basara: concept and design of the article, literature searches, writting the manuscript, approval of the final version;

Nataša Jokić Begić: concept and design of the article, comments on first draft, revisioning the manuscript, approval of the final version;

Sanja Popović Grle: revisioning the manuscript;

Marko Jakopović \& Miroslav Samaržija: revisioning the manuscript.

\section{References}

1. Albuquerque SC, Carvahlo ER, Lopes, RS, Marques HS, Macedo DS, Pereira ED, Hyphantis, TN, Carvahlo, AF: Ego defense mechanisms in COPD: impact on healthrelated quality of life and dyspnoea severity. Qual Life Res 2011; 20:1401-1410

2. Al-Gamal E, Yorke J: Percieved breathlessness and psychological distress among patients with chronic obstructive pulmonary disease and their spouses, Nursing and Health Sciences 2014; 16:103-111

3. Alius, MG, Pané-Farré CA, von Leupoldt A, Hamm, AO: Induction of dyspnea evokes increased anxiety and maladaptive breathing in individuals with high anxiety sensitivity and suffocation fear. Psychophisiology 2013; 50:488-497

4. Allen B, Friedman BH: Positive emotion reduces dyspnea during slow paced breathing. Psychophisiology 2012; 49:690-696

5. American Thoracic Society. Dyspnea Mechanisms, Assessment, and Management: A Consensus Statement. Am J Respir Crit Care Med 1998; 159:321-340

6. Baiardini I, Braido F, Ferraioli G, Menoni S, Bruzzone M, Conte ME, Gani F, Ridolo E, Scordanaglia A, Canonica $G W$ : Pitfalls in respiratory allergy management: Alexithymia and its impact on patient- reported outcomes. $J$ Asthma 2011; 48:25-32

7. Bailey PH: The dyspnea-anxiety-dyspnea cycle-COPD patient's stories of breathlessness: it's scary/when you can't breathe. Qualitative Health Research 2004; 14:760778

8. Blazer DG, Hybels CF: Shortness of breath as a predictor of depressive symptoms in a community sample of older adults. Geriatric Psychiatry 2010; 25:1080-1084 
9. Blechert J, Wilhelm FH, Meuret AE, Wilhelm EM, Walton TR: Experimental, autonomic and respiratory correlates of CO2 reactivity in individuals with high and low anxiety sensitivity. Psychiatry Res 2013; 209: 566-573

10. Bogaerts K, Notebaert K, Van Diest, I, Devriese S, De Peuter S, Van den Bergh O: Accuracy of respiratory symptom perception in different affective contexts. $J$ Psychos Res2005; 58, 537-543

11. Borges-Santos E, Takashi-Wada J, Marques da Silva C, Silva RA, Stelmach $R$, Carvalho CRH, Lunardi AC: Anxiety and depression are related to dyspnea and cinical control but not with thoracoabdominal mechanics in patients with COPD. Respiratory Physiology and Neurobiology 2015;

http://dx.doi.org/10.1016/j.resp.2015.01.011

12. Burkhardt SCA, Wilhelm FH, Meuret AE, Blechert J, Roth WT: Temporal stability and coherence of anxiety, dyspnea and physiological variables in panic disorder. Biol Psychol 2010; 85: 226-232

13. Calikoglu M, Sahin G, Ertekin Yazici A, Yazici K, Ozisik S: Pulmonary muscle strength, pulmonary function tests and dyspnea in women with major depression. J Womens Health 2004; 13:93-98

14. Carrieri-Kohlman V, Donesky-Cuenco D, Kyung Park S, Mackin L, Nguyen HQ, Paul SM: Additional evidence for the affective dimension of dyspnea in patients with COPD. Res Nurs Health 2010; 33:4-19. doi:10.1002/nur.20359

15. Chenivesse CM, Chan PY, Tsai HW, Wheeler-Hegland K, Silverman E, Von Leupoldt A, Similowski T, Davenport P: Negative emotional stimulation decreases respiratory sensory gating in healthy humans. Respiratory Physiology and Neurobiology 2014; 204: 50-57

16. Dahlen I, Jansson C: Anxiety and depression are related to the outcome of emergency treatmentin patients with obstructive pilmonary disease. Chest 2002; 122:1633-7

17. De Peuter S, Van Diest I, Lemaigre V, Verleden G, Demedts M, Van den Bergh O: Dyspnea: The role of psyhological processes. Clin Psychol Rev 2004; 24: 557-581

18. De Voogd JN, Sanderman R, Postema K, van Sonderen E, Wempe JB: Relationship between anxiety and dyspnea on exertion in patients with chronic obstructive pulmonary disease. Anxiety, Stress and Coping 2011; 24:439-449

19. Deshmukh VM, Toelle BG, Usherwood T, O'Grady B, Jenkins CR: Anxiety, panic and adult asthma: A cognitivebehavioral perspective. Respir Med 2007; 101: 194-202

20. Dethlefsen T, Dahlke R: Bolest kao put. Naklada Ljevak d.o.o., 2011

21. Di Marco F, Verga M, Reggente M, Maria Casanova F, Santus P, Blasi F, Allegra L, Centanni, S: Anxiety and depression in COPD patients: The roles of gender and disease severity. Respir Med 2006; 100:1767-74

22. Donesky D, Nguyen Q, Paul SM, Carrieri-Kohlman V: The affective dimension of dyspnea improves in a dyspnea self-management program with exercise training. J Pain Symptom Manage 2014; 47:757-771

23. Hallas CN, Howard C, Theadom A, Wray J: Negative beliefs about breathlessness increases panic for patients with chronic respiratory disease. Psychology, Health \& Medicine 2012; 17:467-477

24. Han JN, Schepers R, Stegen K, Van den Bergh O,Van de Woestijne KP: Psychosomatic symptoms and breathing pattern. J Psychos Res 2000; 49: 319-333

25. Henje Blom E, Serlachius E, Chesney AM, Olsson EMG: Adolescent girls with emotional disorders have a longer end-tidal $\mathrm{CO} 2$ and increases respiratory rate compared with healthy controls. Psychophisiology 2014; 51:412-418

26. Herigstad M, Hayen A, Reinecke A, Pattinson KTS: Development of a dyspnea word cue set for studies of emotional processing in COPD. Respiratory Physiology and Neurobiology 2016; 223:37-42

27. Howren MB, Suls J: The symptom perception hypothesis revised: depression and anxiety play different roles in concurrent and retrospective physical symptom reporting. J Pers Sol Psycho 2011; 1:182-195

28. Ishikawa Y, Takeshima T, Mise J, Ishikawa S, Matsumura M: Physical symptoms in outpatients with psychiatric disorders consulting the general internal medicine division at a Japanese university hospital. International Journal of General Medicine 2015; 8:261-266

29. Khalsa SS, Adolphs R, Cameron OG, Critchley HD, Davenport PW, Feinstein JS, Feusner JD, Garfinkel SN, Lane $R D$, Mehling WE, Meuret AE, Nemeroff CB,Oppenheimer S, Petzschner FH, Pollatos O, Rhudy JL, Schramm LP, Simmons WK, Stein MB, Stephan KE, Van Den Bergh O, Van Diest I, von Leupoldt A, Paulus MP \& the Interoception Summit 2016 participants. Interoception and Mental Health: a Roadmap, Biological Psychiatry: Cognitive Neuroscience and Neuroimaging (2018), doi: 10.1016/j.bpsc.2017.12.004

30. Kuroda T, Masaoka Y, Kasai H, Noguchi K, Kawamura M, Homma I: Sharing breathlessness: investigating respiratory change during observation of breath-holding in another. Respiratory Phisiology and Neurobiology 2012; 180:218-222

31. Leivseth L, Nilsen TIL, Mai X, Johnsen R, Langhammer A: Lung function and anxiety in association with dyspnoea: The HUNT study, Res Med 2012; 106:1148-1157

32. Ley R: Respiration and the Emotion of Dyspnea/ Suffocation Fear. In: Haruki Y., Homma I., Umezawa A., Masaoka Y. (eds) Respiration and Emotion. Springer, Tokyo, 2001

33. Li W, Van Diest I, De Peuter S, Bogaerts, K, Oyen, N, Hombroux, N, Van de Woestijne KP, Gallego J, Van den Bergh O: Repeated experiences of air hunger and ventilatory behavior in response to hypercapnia in the standardized rebreathing test: Effects of Anxiety, Biol Psychol 2008; 77:223-232

34. Martínez-Moragón E, Perpiñá M, Belloch A: Does Experience Influence Perception of Dyspnea? Arch Bronconeumol 2006; 42:171-174

35. Martinez-Rivera C, Del Carmen Vennera M, Canete C, Bardagi S, Picado C: Psychological profile of patients with bronchial asthma and functional dyspnea: a comparison with a non-asthmatic population and impact on the disease. Arch Bronconeumol 2011; 47:73-78

36. Neuman A, Gunnbjornsdottir M, Tunsater A, Nystrom L, Franklin KA, Janson C: Dyspnea in relation to symptoms of anxiety and depression: a prospective population study. Resp Med 2006; 100:1843-1849

37. Nowobilski R: Psychosomatic correlations in patients with bronchial asthma. Pol Arch Med Wewn 1999; 102:1063-7

38. Nowobilski R, Furgal M, Czyz P, de Barbaro B, Polczyk R, Bochenek G, Nizankowska-Mogilnicka E, Szczeklik A: Psychopathology and personality factors modify the perception of dyspnea in asthmatics. J Asthma 2007; 44:203-207

39. Pappens M, Smets E, Van den Bergh O, Van Diest I: Fear of suffocation alters respiration during obstructed breathing. Psychophysiology 2012; 49:829-832 
40. Pappens M, Van den Bergh O, De Peuter S, Bresseleers J, Vansteenwegen D, Van Diest I: Defense reactions to interoceptive threats: A comparison between loaded breathing and aversive picture viewing. Biol Psychol 2010; 84:98-103

41. Peiffer C: Dyspnea and Emotion What Can We Learn from Functional Brain Imaging? Am J Respir Crit Care Med 2008; 177:937-938

42. Petersen S, Ritz T: The association of respiratory sensations with depressive mood is distinct from the association with anxious mood. Personality and Individual Difference 2009; 46:406-411

43. Rietveld $S$, van Beest I: Rollercoaster asthma: When positive emotional stress interferes with dyspnea perception. Behav Res The 2006; 45:977-987

44. Ritz T, Thons M: Airway response of healthy individuals to affective picture series, Int J Psychophysiol 2002; 46:67-75

45. Scano G, Gigliotti F, Stendardi L, Gagliardi E: Dyspnea and emotional states in health and disease. Res Med 2013; 107:649-655

46. Schmidt NB, Richey AJ: Social anxiety symptoms uniquely predict fear responding to $35 \%$ CO2 challenge. J Psychiatr Res 2008; 42:851-857

47. Schön D, Dahme B, von Leupoldt A: Associations between the perception of dyspnea, pain and negative affect. Psychophisiology 2008; 45:1064-1067

48. Serap Monkul E, Onur E, Tural U, Hatch JP, Alkin T, Yucel B, Fidaner H: History of suffocation, state-trait anxiety sensitivity in predicting $35 \%$ carbon-dioxideinduced panic. Psychiatry Res 2010; 179:194-197

49. Sharma P, Morris NR, Adams L: Effect of experimental modulation of mood on perception of exertional dyspnea in healthy subjects. J Appl Physiol 2016; 120:114-120

50. Trueba AF, Smith NB, Auchus RJ, Ritz T: Academic exam stress and depressive mood are associated wuth reductions in exhaled nitric oxide in healthy individuals. Biol Psychol 2013; http://dx..doi.org/10.1016/j.biopsycho.2013.01.017

51. Van Manen JG, Bindels PJE., Ijzermans CJ, van der Zee JS, Bottema BJAM, Schade E: Prevalence of comorbidity in patients with a chronic airway obstruction and controls over the age of 40. JClin Epidemiol 2001; 54:287-93
52. Vancampfort D, Stubbs B, Sienaert P, Wyckaert S, De Hert M, Rosenbaum S, Probst M: What are the factors that influence physical activity participation in individuals with depression? A review of physical activity correlates from 59 studies. Psychiatr Danub $2015 ; 27: 210-224$

53. Von Leupoldt A, Dahme B: The impact of emotions on symptom perception in patients with asthma and healthy controls. Psychophisiology 2013; 50:1-4

54. Von Leupoldt A, Ambruzsova R, Nordmeyer S, Jeske N, Dahme B: Sensory and Affective Aspects of Dyspnea Contribute Differentially to the Borg Scale's Measurement of Dyspnea. Respiration 2006; 73:762-768

55. Von Leupoldt A, Chan PYS, Bradely MM, Lang PJ, Davenport $P W$ : The impact of anxiety on the neural processing of respiratory sensations. Neuroimage 2011; $55: 247-252$

56. Von Leupoldt A, Dahme B: Psychological aspects in the perception of dyspnea in obstructive pulmonary diseases. Res Med 2007a; 101:411-422

57. Von Leupoldt A, Mertz C, Kegat S, Burmester S, Dahme B: The impact of emotions on sensory and affective dimension of perceived dyspnea. Psychophisiology 2006; 43:382-386

58. Von Leupoldt, A, Seemann N, Gugleva T, Dahme B: Attentional distraction reduces the affective but not the sensory dimension of percieved dyspnea. Respiratory Medicine 2007b; 101:839-844

59. Von Leupoldt A, Taube K, Henkhus M, Dahme B, Magnussen H: The impact of affective states on the perception of dyspnea in patients with chronic obstructive pulmonary disease. Biol Psychol 2010a; 84:129-134

60. Von Leupoldt A, Vovk A, Bradely MM, Keil A, Lang PJ, Davenport $P W$ : The impact of emotions on respiratoryrelated evoked potentials. Psychophisiology 2010b; 47:579-586

61. Wong KS, Huang YS, Huang YH, Chiu CY: Personality profiles and pulmonary function of children with sighing dyspnoea. Journal of Paediatrics and Child Health 2007; 43:280-283

Correspondence:

Latinka Basara, MA, univ. spec. clin. psych.

University Hospital Center Zagreb, Department for Respiratory Diseases

Jordanovac 104, 10000 Zagreb, Croatia

E-mail: latinkabasara@gmail.com 